\title{
Assessment of Hydraulic Fish Habitat Condition Using Integrated Toolkit: A Case Study of the Geum River Basin, Republic of Korea
}

\author{
Sangyoung Park*, Jeongkon Kim*†, Ick Hwan Ko*, Angela Arthington**, \\ Gary Jones*** , and Kyung Taek Yum****
}

\begin{abstract}
* K-water Institute, Korea Water Resources Corporation (K-water), 462-1 Jeonmin-dong, Yuseonggu, Daejeon, Republic of Korea († Corresponding Author E-mail: jkkim@kwater.or.kr)

** Australian Rivers Institute of Environmental Science 170 Kessels Road Nathan, Queensland 4111 Australia (E-mail: a.arthington@griffith.edu.au)

*** eWater CRC (eWater Ltd.), University of Canberra, GPO Canberra, 2601, ACT Australia (E-mail: gary.jones@ewatercrc.com.au)

**** Dam \& Watershed Dept., Korea Water Resources Corporation (K-water), San 6-2, Yeonchukdong Daedeok-gu, Daejeon 306-711, Republic of Korea (E-mail: yumkt@kwater.or.kr)
\end{abstract}

\begin{abstract}
Artificial changes of river including construction and operation of dam inevitably leads to physical and ecological changes throughout waterways and their floodplains. In this study, a conceptual model coupled with integrated numerical modeling is presented for hydraulic fish habitat assessment of the Geum River basin, Republic of Korea. Based on the major events which might have affected the ecological system, a conceptual model was formulated to guide desktop and field studies, modeling and scenario evaluations. The result of hydraulic fish habitat assessment indicated that the construction of the Daecheong Multipurpose Dam (DMD) in the Geum River basin has altered flow magnitudes and reduced the river's flow variability. Changes are evident in the magnitude of medium and small flows and the river experiences increased low flows during the dry season. Black shiner, an endangered fish species in Korea, was selected and analyzed to explore relationships between flow regime change by dams and changes to its preferred habitats. As a result, fewer sensitive riffle-benthic species were observed in the reaches downstream of DMD due to the reduction of suitable habitat conditions such as riffle-pool sequences. The proposed conceptual model and integrated toolkit would allow river managers to isolate the physical and biological effects associated with dam operation and could be useful for developing river management strategies.
\end{abstract}

Keywords Dam Operation; Eco-hydrology; Fish Habitat; River Assessment

\section{INTRODUCTION}

Most major rivers in Korea have experienced extensive modifications including construction of artificial structures, such as multipurpose dams for flood protection, water supply, hydroenergy generation, and other purposes. The construction and operation of such a dam inevitably leads to physical and ecological changes throughout waterways and their floodplains, mostly downstream of the reservoir, as well as within the reservoir itself and in some cases, also upstream. Downstream impacts are developed through discontinuity in longitudinal gradients, and most of all in modification of the flow regime. These impacts consequently lead to secondary changes in fluvial and floodplain processes, affecting the high spatial and temporal variability of available habitats characteristic of river floodplain systems. These primary and secondary changes have biological and socio-economic implications.

Since the 1990s, many river restoration projects have been initiated in Korea, focusing on improving physical characteristics of river channels and water quality to facilitate public use. 
The alterations to the natural flow regime (flow magnitude, frequency, duration, timing, and rate of change) can, directly or indirectly, influence secondary physical processes and thus have deleterious impacts on ecological integrity (Poff et al., 1997). Richter et al. (1996) proposed the index of hydrologic alteration as a tool to quantify hydrologic alterations and compare natural and altered flow regimes. However, less attention has been paid to understanding flow regime changes and their ecological consequences. Methodologies are required to quantitatively determine the effects of dam operations, one of the main factors altering flow regimes, on downstream habitat and ecological conditions. They should be flexible so as to accommodate the varied conditions found throughout river basins.

Currently two main approaches are used to isolate effects of anthropogenic disturbances from effects of natural environmental factors. One of them is application of analytical techniques in which natural variability is taken into account by mathematical methods. These are multivariate statistical methods (Leps and Smilauer, 2003) and mathematical modelling methods such as artificial neural networks (Cereghino et al., 2003; Park et al., 2004). Another, more direct, approach is to find a community metric independent of natural environmental factors and therefore stable along gradients of natural factors (e.g. river continuum), yet sensitive to anthropogenic disturbance (Beketov and Liess, 2008). However, there is little knowledge as to what quantitative components of the hydrologic regime are really important for maintenance of ecosystem function, which ones are less important and which components of the natural regime can be changed and how (Bunn and Arthington, 2002).

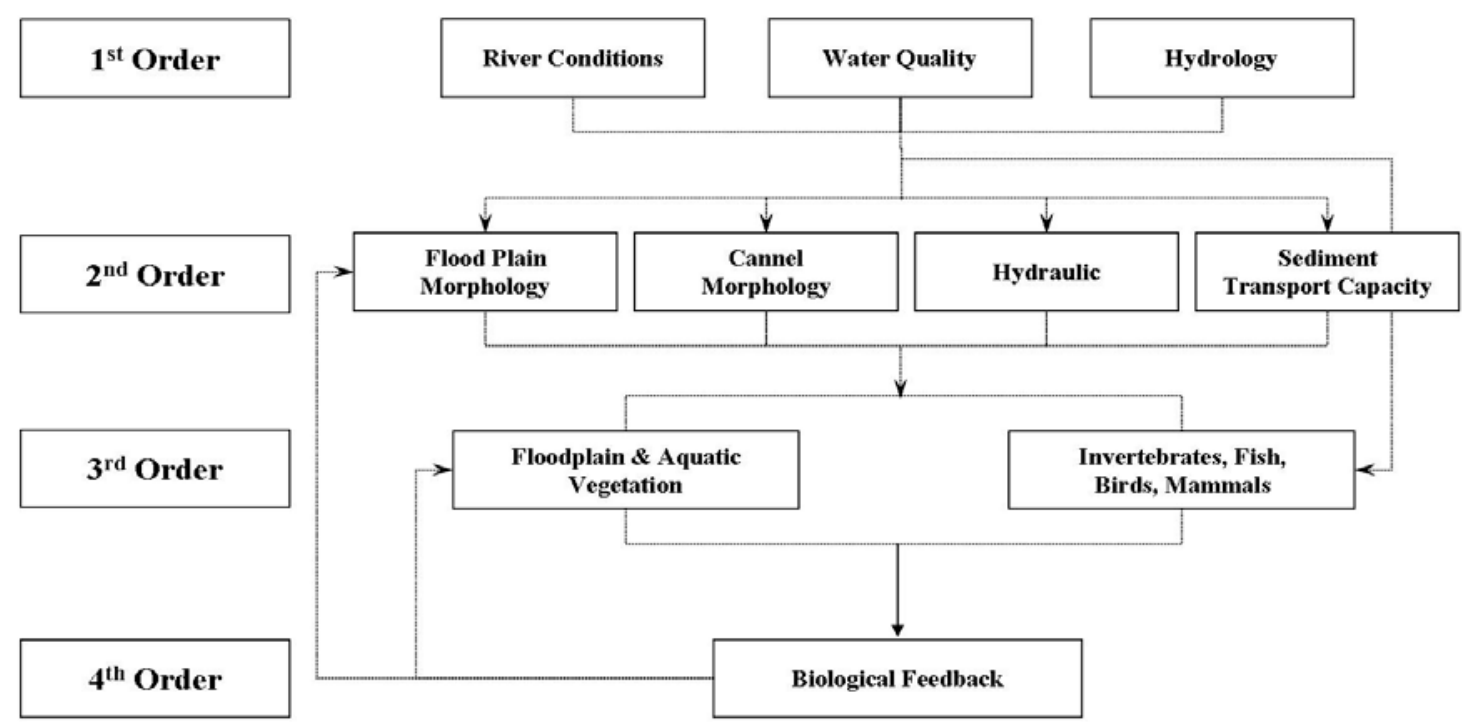

Figure 1. Systematic order of impacts on a river environment (Jorde, 2006)

Recently, Jorde (2006) conceptualized a systematic order of impacts on a river environment as illustrated in Figure 1. The first order of impact represents the immediate physical responses due to the presence of the dam and reservoir. Depending on the size of the reservoir and operational mode the flow regime is altered, the reservoir acts as a trap for sediments and nutrients and the water quality may change due to the residence time and biogeochemical processes within the reservoir. The second order is also comprised of physical processes downstream of the dam, but produced primarily as a consequence of the impacts of the previous order. Examples of hydraulic changes include water depths and velocities, shear stress and sediment size and composition. These physical responses lead to 
the above morphological changes within channels and on floodplains. The third order represents biological impacts and ecological responses, such as the composition of plant and fish communities, due to the physical changes indicated primarily by the second order of impacts. Finally, the fourth order represents the biological feedback that may alter the second and third orders of impact on the river system. Examples of the fourth order impacts are changes in floodplain roughness due to vegetation growth that then alters the hydraulic characteristics of the affected river reach, or the loss of large woody debris which can bring about changes on channel structure. Each of the four orders of impact requires separate modeling processes. The first order determines the model's physical upstream boundary conditions followed by the hydraulic and transport models in the second order. Biological simulations are performed as third order responses to physical changes. Finally, the fourth order is a feedback process that supplies changed initial conditions to the second and third orders for future simulations.

In this study, a conceptual model coupled with numerical modeling is presented for the Geum River basin, Korea. The methodology will: (1) isolate operational impacts from other basin changes, (2) assess the impacts of dam operation-based influences on downstream physical processes, (3) link physical process evaluation with biological processes and ecological function, and (4) be used in a predictive capacity. These qualities of the conceptual and numerical models will allow river managers to isolate the physical and biological effects associated with the dam operation in the basin and develop river management strategies to mitigate those effects. There are many physical and biochemical factors, such as water quality and geomorphologic conditions, which could affect the fish community. All the factors need to be better understood before any remedial actions can be taken to positively restore the ecosystem, especially the fish community. However, the flow regime change has been regarded as one of the key drivers affecting the fish community by altering river and floodplain ecosystems (Bunn and Arthington, 2002). Therefore, this paper focused on the hydraulic fish habitat changes caused by flow regime alteration by employing a suit of river basin analysis models.

\section{GEUM RIVER BASIN}

The Geum River basin is the third largest river basin in Korea, situated in the west of the central part of the Korean peninsula. It occupies an area of $9,835.3 \mathrm{~km}^{2}$, almost one tenth of the country, and extends from east to the west for about $130 \mathrm{~km}$ and from north to the south for about $160 \mathrm{~km}$. To the north and east the Geum River basin borders on the Han and the Nakdong River basins and its southern part borders on the Mangyeong and the Seomjin River basins. The west of the basin lies the Yellow sea. There are two multipurpose dams in the Geum River basin; one is the Daecheong Multipurpose Dam (DMD) and the other is the Yongdam Multipurpose Dam (YMD). These features of the Geum River basin are shown in Figure 2. The Daecheong Multipurpose Dam, constructed in December 1980, is the first multipurpose dam in the Geum River basin. It is located at about $150 \mathrm{~km}$ upstream from the estuary of the Geum River which flows into the Yellow sea from the middle part of the Korean peninsula. The crest elevation of DMD is EL. $83 \mathrm{~m}$ (72 m high from ground level) and $495 \mathrm{~m}$ long. The dam type is unique, being a hybrid style of concrete gravity and rock fill dam. The total storage capacity is $1,490 \mathrm{Mm}^{3}$.

The Yongdam Multipurpose Dam, constructed in October 2001, diverts the Geum River water resources into the Mangyeong River basin area, which lacks municipal and industrial water supplies. The crest elevation is EL. $268.5 \mathrm{~m}$ (70 m high from ground level) and $498 \mathrm{~m}$ long. The dam type is a concrete faced rock-fill dam. The total storage capacity is $815 \mathrm{Mm}^{3}$ 
and part of this reservoir's water flows through a diversion tunnel with length and diameter of $21.9 \mathrm{~km}$ and $3.2 \mathrm{~m}$, respectively. Mean annual stream flow of the whole Geum River basin for the period of 1983 to 2001 is $222.0 \mathrm{~m}^{3} / \mathrm{sec}$ or $7000.0 \mathrm{Mm}^{3} /$ year. Annual streamflow varies widely as annual rainfall fluctuates. The annual maximum stream flow is almost double the annual mean, whereas the annual minimum is nearly half of the mean (Table 1).

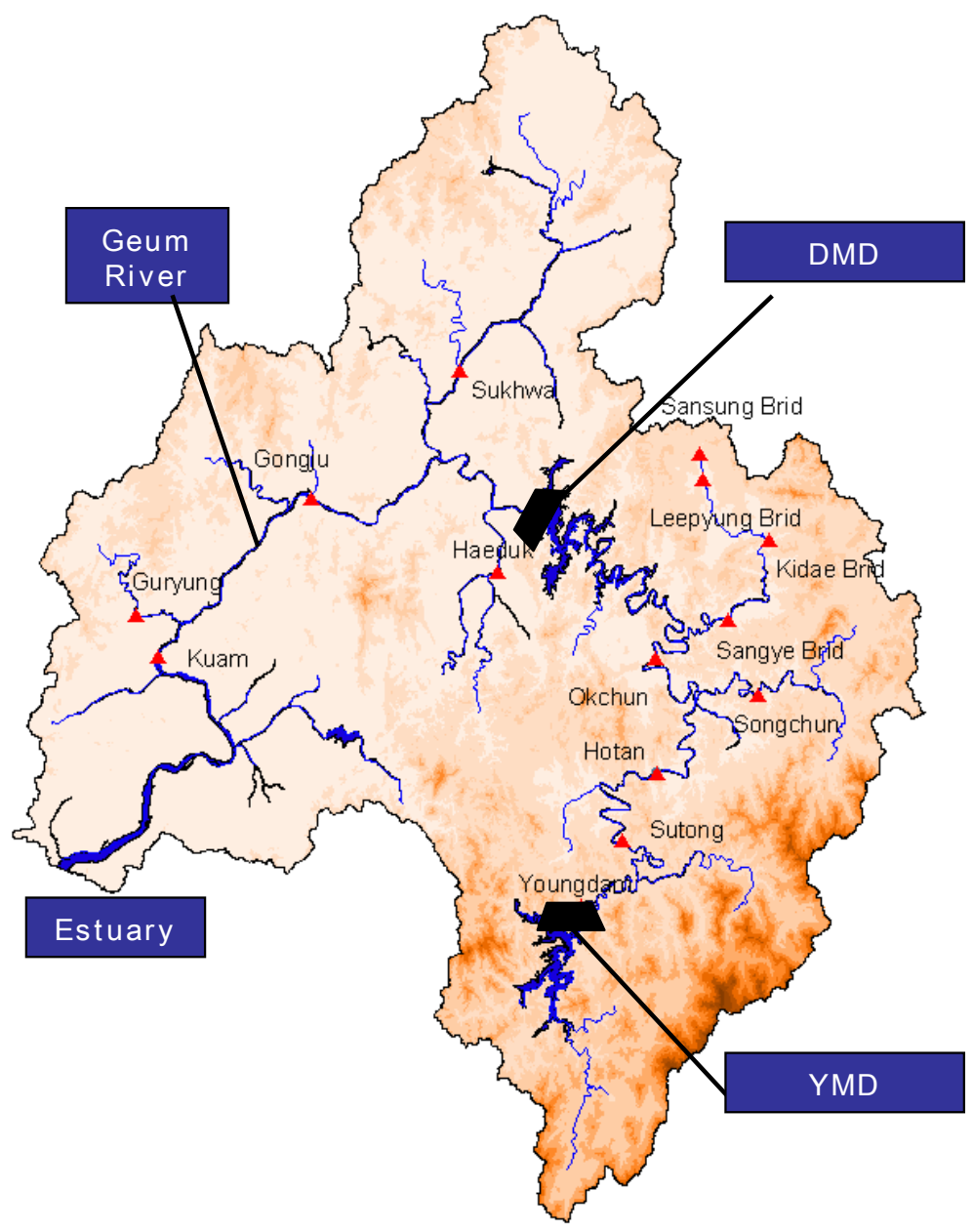

Figure 2. Map of the Geum River Basin with major features

Table 1. Annual maximum, minimum and mean rainfall and stream flow (1983-2001)

\begin{tabular}{llccc}
\hline & \multicolumn{2}{c}{ Rainfall } & \multirow{2}{*}{ Streamflow $\left(\times 10^{9} \mathrm{~m}^{3}\right)$} & Runoff coefficient (\%) \\
\cline { 2 - 4 } & $\mathrm{mm}$ & $\times 10^{9} \mathrm{~m}^{3}$ & & 58.3 \\
Mean & 1221.6 & 12.0 & 7.0 & 67.3 \\
Maximum & 1714.6 & 16.8 & 11.3 & 47.0 \\
Minimum & 670.7 & 6.6 & 3.1 & \\
\hline
\end{tabular}

\section{CONCEPTUAL MODEL}

A conceptual model has three major purposes. First, it establishes the systematic template of a specific catchment or floodplain with all contributing impacts, second it identifies reference scenarios and compares those with the contemporary or any other impacted situation, and 
Geum River basin has been developed to provide a framework for structuring, analysing, and quantifying the impacts of altered hydrologic regimes below dams on the ecosystem.

As shown in Figure 3, the initial situation of the physical template and the hydrological regime of the Geum River basin is the pristine state where there are no dams in the basin. The physical template is then changed by the DMD constructed in the middle of the basin in 1980. Additionally, the YMD was built upstream of DMD in 2001, which changed the hydrological regime downstream of this dam. The horizontal arrows show the combination of different historic situations as compared to the current situation. The modeling processes will follow these pathways, thus producing comparable sets of results describing the physical processes for different historic conditions and the present situation. In addition, virtual situations can be constructed and modelled, such as a combination of current floodplain conditions and the historic hydrological regime. In a further step, the results of the physical process modeling can be coupled with biological interfaces that model habitat quality for certain organisms or groups of organisms, if such interfaces are available. In a final step, the results for different scenarios of infrastructure and flow management are quantitatively compared. Other major events that were expected to affect various conditions of the river in one way or another were also identified.

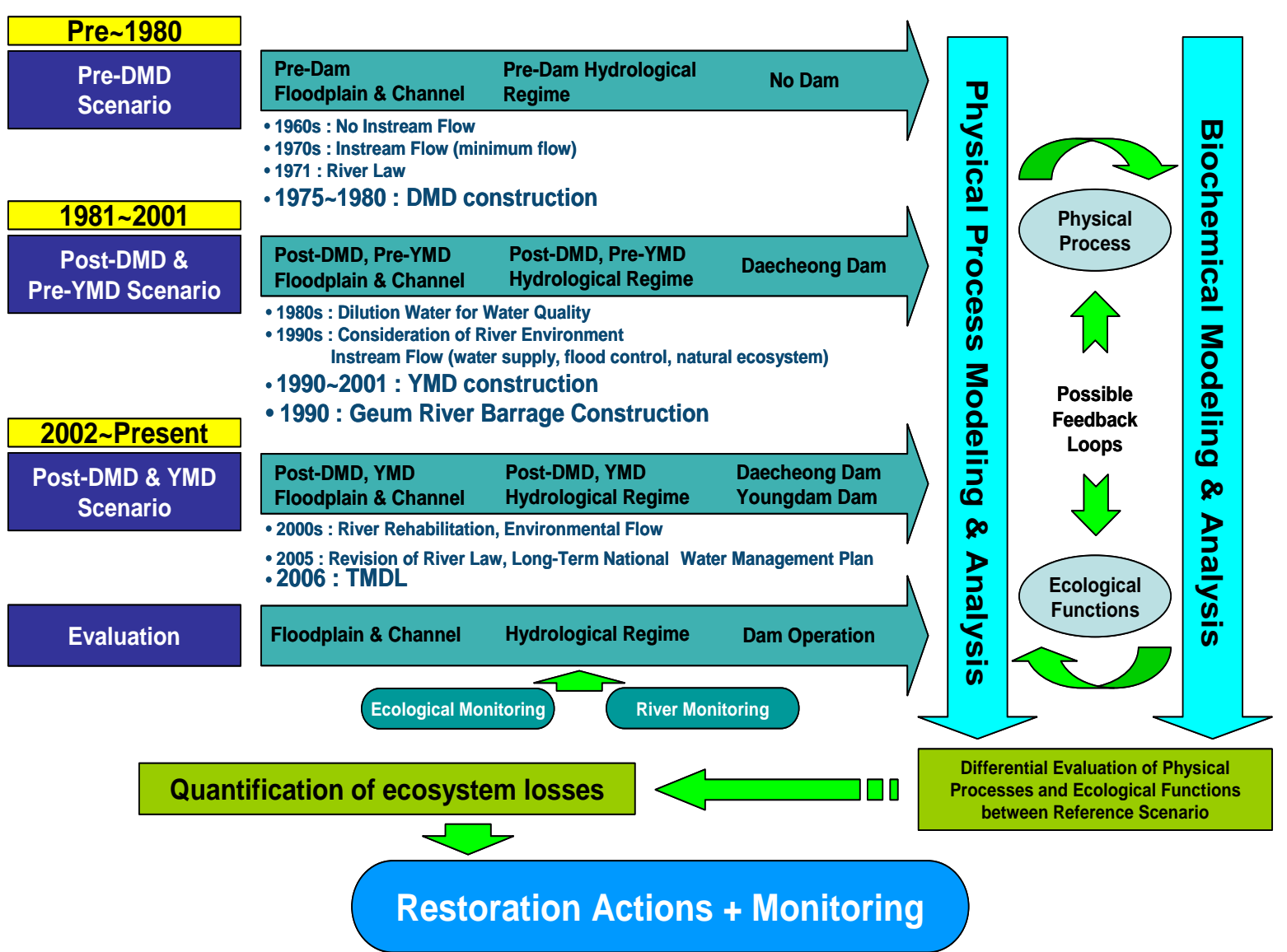

Figure 3. Conceptual model for the Geum River Basin

\section{FLOW GENERATION AND ANALYSIS}

The task of eco-hydrological river assessment calls for a range of hydraulic, hydrological and ecological data. As a first step, the inflow from 14 sub-basins in the Geum River basin was estimated from the Rainfall Runoff Forecasting System (RRFS). Next, the KModSim 
network simulation model developed jointly by Korea Water Resources Corporation and Colorado State University was used to generate the unregulated flow regime based on the water demand and the dam operation record. HEC-RAS model was used to estimate the river hydrologic parameters. Finally, the River Analysis Package (RAP), a toolbox of quantitative techniques for environmental flow assessment and management, was employed to estimate flow regime change and ecological implications.

\section{RESULTS AND DISCUSSION}

\section{Geomorphic Changes in the Geum River}

The bed slope in a river is a very crucial factor to distinguish river characteristics. It is also very important to understand sediment yield in a watershed, providing a key factor to determine bed elevation change in a river. In general, the river bed is continually changed by natural factors such as fluctuation of discharge due to rainfall, geomorphic characteristics, bed materials, land covered with vegetation, and by human activity including dam and hydraulic structures, levee banks, dredging, and land use changes.

The bed elevation in the Geum River from 1988 to 2002 was degraded about $0.7 \mathrm{~m}$ at 34.16 $\mathrm{km}$ downstream of the DMD. The Geum River estuary barrage was constructed in 1990 and the gates in the barrage were fully opened until 1994. The fine sediment particles discharged from the DMD reservoir settled near the barrage and were flushed out to the sea during the flood season. The river bed in the midstream was degraded by $2.7 \mathrm{~m}$ at $91.20 \mathrm{~km}$ because of the DMD constructed in 1980. Degradation was due to the downstream impact of dam construction, reduction in the magnitude of flood peaks and marked decrease in the sediment load, especially in those reaches immediately below the dam. In addition, dredging of the river sand and gravel affected river bed degradation. This type of bed degradation affects the stability of hydraulic structures such as bridge scouring, decrease of intake ability, bank erosion, increase of vegetated areas, and decrease of aquatic habitat. The instability of river and bed changes makes it difficult to manage and plan rivers. The channel width measured from levee to levee did not change significantly along the main stream because of the embankment work.

\section{Flow Regime Change}

\section{General statistics}

Flow regime change caused by dam operations and flow management was analyzed for the two gauging stations, SuTong (downstream of the YMD) and GongJu (downstream of the DMD). The natural flow of the Geum River was generated using KModSim for the period 1984 to 2006, based on the dam construction scenario.

Table 2. Statistics of flow regime change at SuTong and GongJu station (unit: $\mathrm{m}^{3} / \mathrm{sec}, \mathrm{cms}$ )

\begin{tabular}{ccccc}
\hline Unregulated & Regulated & & Regulated & Regulated \\
Flow, & Flow, & Unregulated & Flow & Flow \\
SuTong & SuTong & Flow & GongJu & GongJu \\
(without & (with & GongJu & (with DMD & (with DMD \\
YMD) & YMD) & & only) & and YMD) \\
\hline
\end{tabular}




\begin{tabular}{lccccc}
\hline Percentile 10 & 55.5 & 44.2 & 275.7 & 264.6 & 253.5 \\
Percentile 90 & 2.4 & 6.1 & 6.8 & 30.0 & 30.0 \\
Mean annual flow & 30.3 & 27.7 & 140.9 & 139.3 & 136.5 \\
CV & 2.9 & 2.3 & 2.9 & 2.0 & 1.9 \\
\hline
\end{tabular}

2

3

4

5

6

The general statistics produced by the time series analysis (TSA) module in RAP for the two gauging stations are summarized in Table 2. The result of TSA indicates that the low flow (90 percentile) has increased and high flow (10 percentile) has decreased as a consequence of flow regulation associated with dam construction. The coefficient of variation (CV - division of mean annual flow by its standard deviation) shows reduced annual flow variability after construction of both dams. The flow regime of GongJu gauging station is significantly affected by the DMD and the YMD has little effect on flow regime change.

\section{Temporal variation}

The result of temporal variation analysis for SuTong gauging station shows decreased total monthly flow in monsoon seasons (July, August and September) and increased flow in other months. Flow variability is especially reduced in spring (March, April and May) (Figure 4). The flow variability at GongJu station (not shown in this paper) is rather smaller than at SuTong station, which appears to be due to its location downstream of DMD and to the influence of variable inflows from tributaries.

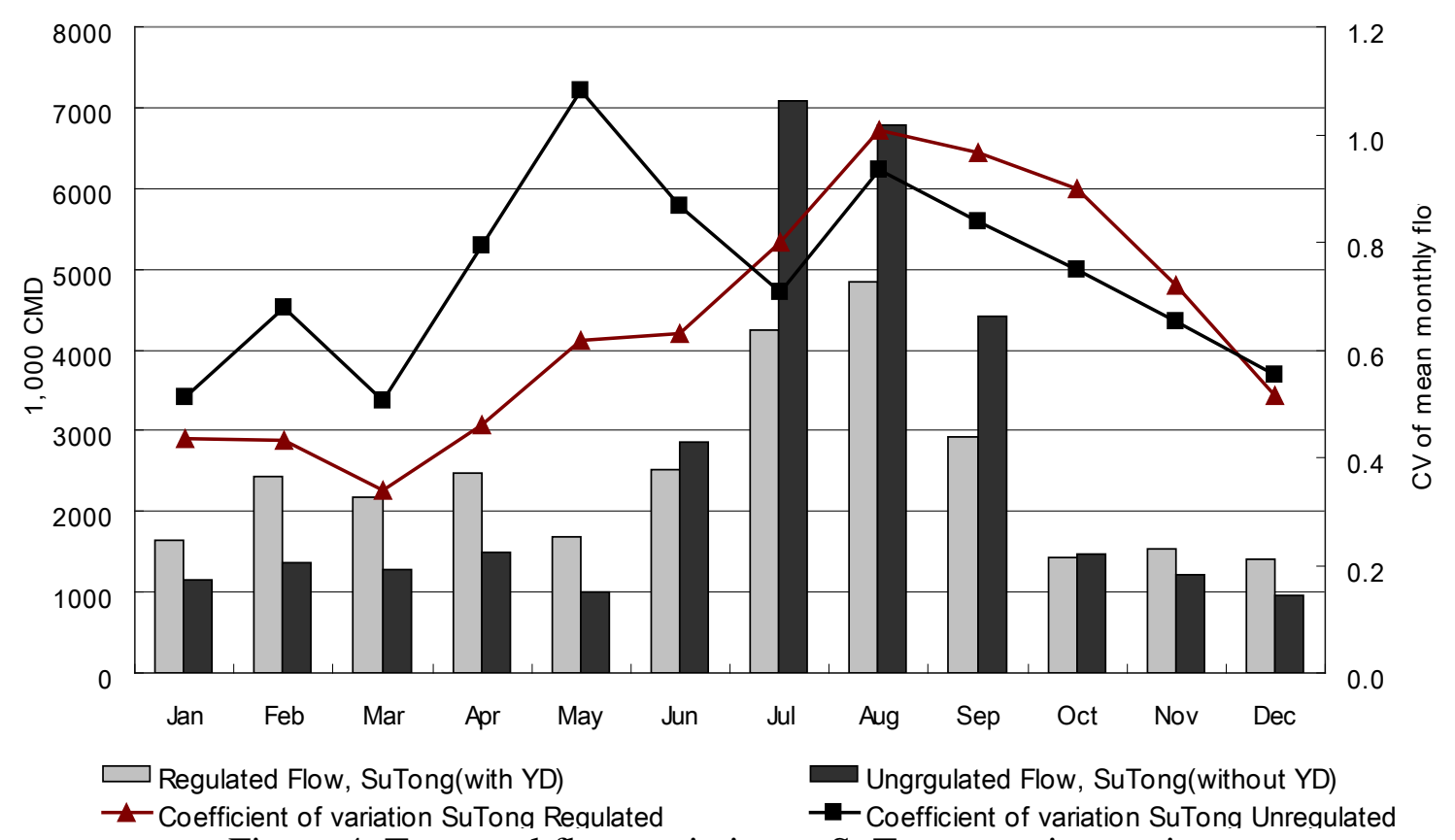

Figure 4. Temporal flow variation at SuTong gauging station

\section{Fish Community Change}

Changes in the fish community of the Geum River before and after dam construction were examined to determine the relationships with flow regime change, and to suggest appropriate flow requirements for freshwater fish. Fish are generally considered to be a significant component of aquatic ecosystems by virtue of their potential to influence (either directly or indirectly) the physical characteristics of aquatic environments, the structure and composition of biological assemblages and the functioning of aquatic and terrestrial ecological processes (Heins and Mattews, 1987; Mattews, 1998; Arthington et al., 2003). 
Based on previous investigations, the fish fauna in the reaches upstream and downstream of the DMD were notably different. Five introduced fish species were collected from 2002 to 2004 downstream of the DMD, and about 30 native fish species have not been found during these years. The missing species were either too rare to be captured or they may have become locally extinct. Many of them are Korean endemic species and seem likely to be very sensitive to alteration of the flow regime and/or habitat structure. Survey results suggest that sensitive riffle-benthic species have been lost due to the reduction or alteration of suitable habitat conditions such as riffle-pool sequences. Although the YMD was built recently (in 2001), there were some changes in the fish fauna upstream and downstream of the YMD, indicating that this dam may have had a similar negative impact on the species composition of the fish community. The effects of flow regime change on a representative fish species are explored in the following section.

\section{Hydraulic Metric Analysis}

Quantitative understanding of the impact of flow regime change on ecological systems is of great importance on both ecosystem conservation and reservoir operation. The term 'hydraulic metric' refers to any quantifiable aspect of the river that is a function of flow. The depth, velocity and area of flow are all simple hydraulic metrics (Marsh, 2004).

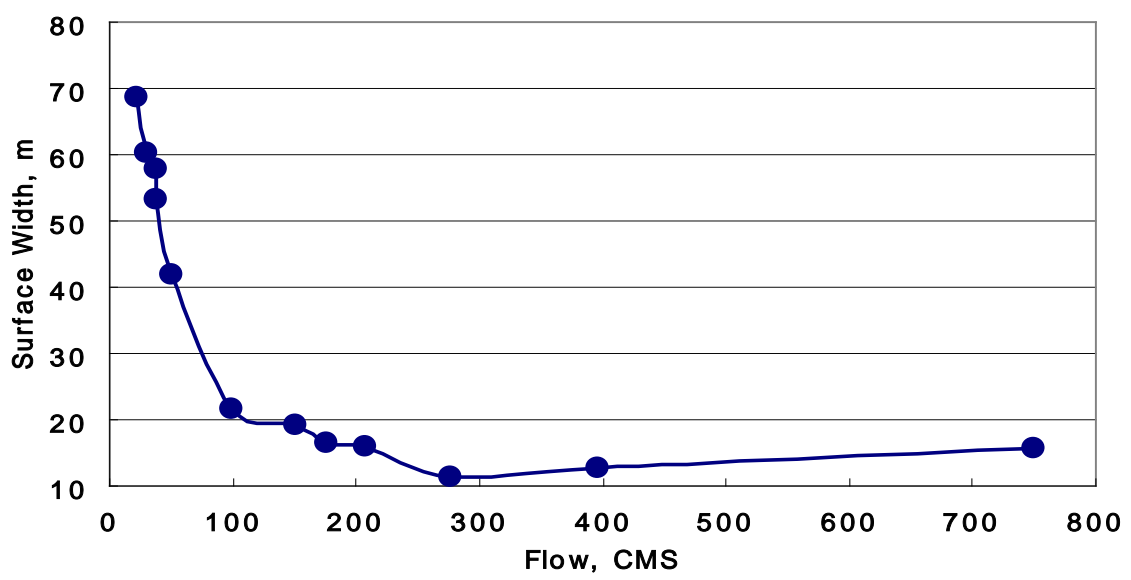

(a) Section B

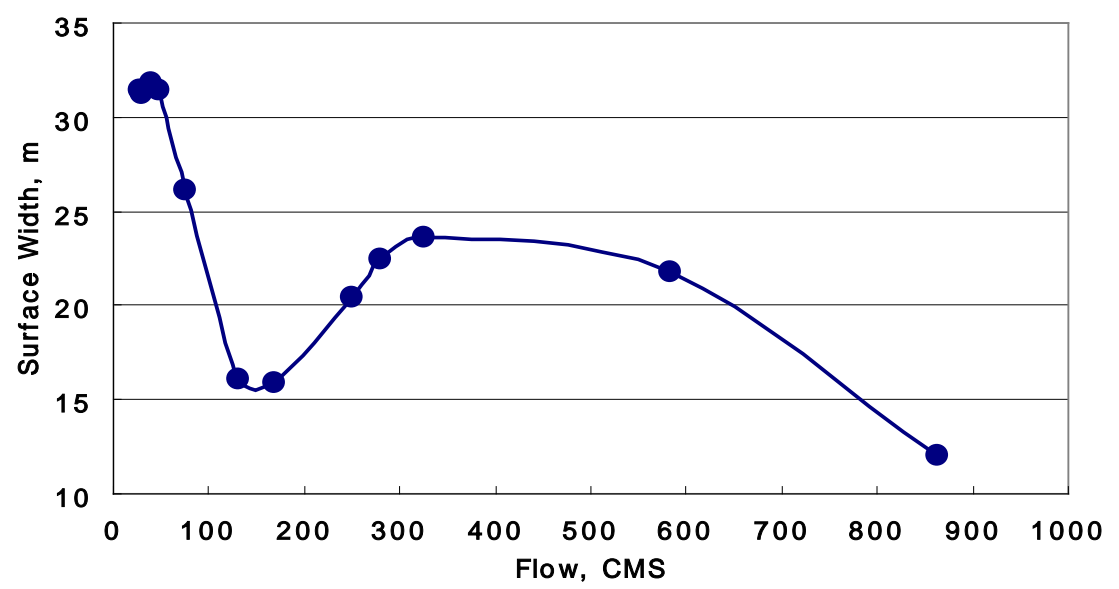

(b) Section A

Figure 5. Rating curves for black shinner habitat rules in two sections of the Geum River 
Black shinner (Pseudopungtungia nigra), designated as endangered species by the Korean Ministry of Environment, was chosen to analyse flow-ecology relationships in this study. The habitat conditions occupied by black shiner were investigated in the Geum River in 2007. Preferred habitats have velocity less than $0.08 \mathrm{~m} / \mathrm{sec}$ and a mean depth of $0.82 \mathrm{~m}$ and those values were used to estimate hydraulic metrics using Hydraulic Analysis (HA) module in RAP. Hydraulic metric analysis was carried out for two sections of the Geum River suitable for exploring the impact of dam operation: one is downstream of the DMD (section B) and the other is mid-downstream beyond the Miho stream confluence (section A). The results are presented in the Figure 5 as the surface width of all the submerged points in the cross section where the velocity and depth rules presented above are true. The rating curves, calculated for each river section, indicate the variation of average surface width of the part of the channel which meets the velocity and depth conditions of black shinner. The optimum flow to provide suitable habitat in each section is calculated as $39.46 \mathrm{~m}^{3} / \mathrm{sec}$ in Section A and $21.32 \mathrm{~m}^{3} / \mathrm{sec}$ in Section B.

\section{SUMMARY AND CONCLUSIONS}

In this study, a conceptual model is developed for the systematic analysis of hydrological and ecological effects caused by modification of flow in the Geum River basin. The result of time series analysis indicates that low flows (90 percentile) have increased and high flows (10 percentile) have decreased as a consequence of flow regulation associated with dam construction and flow management in the river. Flow variability is especially reduced in the spring season (March, April and May) at the SuTong gauging station below YMD. Loss of high flows and elevated low flows during normally dry months, interacting with reduced flow variability, may have ecological consequences related to alteration of habitat structure (Bunn and Arthington, 2002; Arthington et al., 2003).

Black shinner (an endangered fish species) was selected and analyzed to explore relationships between flow regime change by the two dams and changes to its preferred habitats in two river reaches. Rating curves for each river section indicate that the optimum flows required to provide suitable habitat (riffles) in each reach are $39.46 \mathrm{~m}^{3} / \mathrm{sec}$ and $21.32 \mathrm{~m}^{3} / \mathrm{sec}$. Considering the current flow regime, those estimated optimum flow is similar to the low flow at GongJu (90 percentile: $30 \mathrm{~m}^{3} / \mathrm{sec}$ ).

The assessments of this paper mainly focused on the impact of dam construction to fish habitat change. However, the conceptual and modeling approaches developed for a future whole-of-river assessment can be used for fish, vegetation, and water quality along the main channel as well as the major tributaries of the Geum River. Furthermore, the proposed method can efficiently be integrated with the existing tools such as SPEAR (Beketov and Liess, 2008) for the river management. The intent is to produce a suite of biological parameters that define ecological structure and function and then to conduct habitat condition assessments and estimate the flows required to maintain suitable habitat for each section of the river.

\section{ACKNOWLEDGEMENT}

This research was partly supported by a grant (code\#1-6-3) from Sustainable Water Resources Research Center of 21st Century Frontier Research Program. 


\section{REFERENCES}

3 Arthington, A. H., J. L. Rall, M. J. Kennard and B. J. Pusey. 2003. Environmental flow requirements of fish in Lesotho Rivers using the DRIFT methodology. River Research and Applications, 19 (5-6), pp. 641-666.

Beketov M.A. and L. Matthias, 2008. An indicator for effects of organic toxicants on lotic invertebrate communities: Independence of confounding environmental factors over an extensive river continuum, Environmental Pollution, 156, pp.980-987.

Bunn, S. E. and A. H. Arthington. 2002. Basic principles and consequences of altered hydrological regimes for aquatic biodiversity. Environmental Management, 30, pp. 492507.

Cereghino, R., Park, Y., Compin, A., Lek, S., 2003. Predicting the species richness of aquatic insects in streams using a limited number of environmental variables. Journal of the North American Benthological Society 22, 442-456.

Heins, W. J. and D. C. Mattews. 1987. Historical perspectives on the study of community and evolutionary ecology of North American stream fishes. In: Community Ecology of North American Stream Fishes (Eds D. C. Mattews and W. J. Heins), University of Oklahoma Press: London, pp. 3-7.

Jorde, K. 2006. Reservoir Operations and Ecosystem Losses, The 2nd International Workshop on River Environment, KICT, Korea, pp. 41-66.

Leps and Smilauer. 2003. Multivariate Analysis of Ecological Data Using CANOCO. Cambridge University Press, Cambridge, UK.

Marsh, N. 2004. River Analysis Package Users Guide, CRC for Catchment Hydrology, Australia.

Mattews, W. J. 1998. Patterns in freshwater fish ecology. Chapman and Hall, New York.

Park, Young-Seuk, Tae-Soo Chon, Inn-Sil Kwak, and Sovan Lek. 2004. Hierarchical community classification and assessment of aquatic ecosystems using artificial neural networks, Science of Total Environment, 327, pp.105-122.

Poff, N. L., Allan, J. D., Basin, M. B., Karr, J. R., Presegarrd, K. L., Ritcher, B. D., Sparks, R. E., and Stromberg, J. A. 1997. The Natural Flow Regime, Bioscience, 47(11), pp. 769784.

Richter, B. D., Baumgartner, J. F., Powell, J., and Braun, D. P. 1996. A Method for Assessing Hydrologic Alterations within Ecosystems, Conservation Biology, 10(4), pp. 163-1174. 